\title{
Hypoxia-inducible factor-I alpha, in association with inflammation, angiogenesis and MYC, is a critical prognostic factor in patients with HCC after surgery
}

\author{
Chen-Xin Dai ${ }^{\dagger 1}$, Qiang Gao ${ }^{\dagger 1}$, Shuang-Jian Qiu${ }^{1}$, Min-Jie Ju${ }^{1}$, Ming-Yan Cai ${ }^{1}$, \\ Yong-Feng $\mathrm{Xu}^{1}{ }^{1}$, Jian Zhou ${ }^{1}$, Bo-Heng Zhang ${ }^{1,3}$ and Jia Fan*1,2
}

\author{
Address: ${ }^{1}$ Liver Cancer Institute, Zhongshan Hospital and Shanghai Medical School, Fudan University, Shanghai, PR China, ${ }^{2}$ Institute of \\ Biomedical Sciences, Fudan University, Shanghai, PR China and ${ }^{3}$ Center for Evidence Based Medicine, Fudan University, Shanghai, PR China \\ Email: Chen-Xin Dai - daichenxin@gmail.com; Qiang Gao - qgao1981@gmail.com; Shuang-Jian Qiu - qiu.shuangjian@zs-hospital.sh.cn; Min- \\ Jie Ju - juminjie@hotmail.com; Ming-Yan Cai - catcai@gmail.com; Yong-Feng Xu - xuyongfengsh@gmail.com; \\ Jian Zhou - jianzhou99@yahoo.com; Bo-Heng Zhang - bzhang@zshospital.com; Jia Fan* - jiafan99@yahoo.com \\ * Corresponding author †Equal contributors
}

Published: I December 2009

BMC Cancer 2009, 9:418 doi:10.1186/147|-2407-9-418
Received: 24 June 2009

Accepted: I December 2009

This article is available from: http://www.biomedcentral.com/I47I-2407/9/4I8

(C) 2009 Dai et al; licensee BioMed Central Ltd.

This is an Open Access article distributed under the terms of the Creative Commons Attribution License (http://creativecommons.org/licenses/by/2.0), which permits unrestricted use, distribution, and reproduction in any medium, provided the original work is properly cited.

\begin{abstract}
Background: Despite well-studied tumor hypoxia in laboratory, little is known about the association with other pathophysiological events in the clinical view. We investigated the prognostic value of hypoxia-inducible factor-I alpha (HIF-lalpha) in hepatocellular carcinoma (HCC), and its correlations with inflammation, angiogenesis and MYC oncogene.
\end{abstract}

Methods: In a random series of I 10 HCC patients, the mRNA of HIF- Ialpha, inflammation related factors (COX-2, MMP7 and MMP9), angiogenesis related factors (VEGF and PDGFRA) and MYC in tumor tissue were detected by real-time RT-PCR and HIF-Ialpha protein was assessed by immunohistochemistry. The correlations between HIF-Ialpha mRNA and the factors mentioned previously, the relationship between HIF-Ialpha and clinicopathologic features, and the prognostic value were analyzed.

Results: The expression of both HIF-lalpha mRNA and protein in HCC were independent prognostic factors for overall survival (OS) $(P=0.012$ and $P=0.021$, respectively) and disease-free survival (DFS) ( $P=0.004$ and $P=0.007$, respectively) as well. Besides, the high expression of HIFIalpha mRNA and protein proposed an advanced BCLC stage and more incidence of vascular invasion. The mRNA of HIF-lalpha had significantly positive correlations to that of COX-2, PDGFRA, MMP7, MMP9, MYC, except VEGF. In addition to HIF-Ialpha, COX-2 and PDGFRA were also independent prognosticators for OS $(P=0.004$ and $P=0.010$, respectively) and DFS $(P$ $=0.010$ and $P=0.038$, respectively) .

Conclusion: HIF-Ialpha in HCC plays an important role in predicting patient outcome. It may influence HCC biological behaviors and affect the tumor inflammation, angiogenesis and act in concert with the oncogene MYC. Attaching importance to HIF-Ialpha in HCC may improve the prognostic and therapeutic technique. 


\section{Background}

HEPATOCELLULAR carcinoma (HCC) is the sixth most common cancer and the third most common cause of death from cancer worldwide, with increasing incidence in western countries [1]. Surgical resection provides an opportunity for cure, but the outcome remains dismal due to frequent tumor recurrence. Recently, better appreciations of the role that tumor microenvironment plays in tumor progression have bring a paradigm shift in developing strategies for cancer management. As a consequence, renewed emphasis has been placed on key features of the tumor microenvironment, in particular hypoxia, leading us to explore hypoxia related parameters for more accurate classification of this fetal disease.

As is well-recognized, hypoxia is a common mechanism in HCC as the solid tumor owing to aberrant visualization [2]. Accumulating data have shown that hypoxia can stimulate proliferation[3], induce angiogenesis [4], accelerate invasion [5] and is responsible for treatment resistance in HCC [6]. The adaptation of HCC cells to tissue hypoxia is of central importance for tumor progression, where inducing the ubiquitous transcription factor of hypoxiainducible factor-1 $\alpha$ (HIF-1 $\alpha$ ) expression appears to be a critical step [7].

HIF- $1 \alpha$ is a master regulator of essential adaptive responses to hypoxia, whose expression and transcriptional activity increasing exponentially with decreases in levels of cellular oxygen. In tumors, HIF- $1 \alpha$ regulates proliferation, apoptosis, metastatic spread, and glucose metabolism by acting as a transcription factor for crucial proteins [8].

Previous studies have been focusing on the clinical significance as well as experimental models of HIF-1 $\alpha$ in many types of cancer, which have led to somewhat controversial results $[9,10]$. On the basis of its unquestioned role as a central regulator of tumor pathophysiology, elucidating HIF-1 $\alpha$ 's prognostic value in HCC is of great clinical importance, which may lead to better patient stratification and provide rational for hypoxia targeted therapies.

Importantly, the presence of hypoxia is always associated with and accompanied by inflammation and angiogenesis $[11,12]$. Specifically, HIF-1 $\alpha$ and the oncogene MYC, which is also a transcription factor, act in concert to "fine tune" cancer cells' adaptive responses to hypoxic environments [13].

In the present study, we measured mRNA expression of HIF- $1 \alpha$ in tumor tissue from 110 randomly selected HCC patients. We found that HIF-1 $\alpha$ expression was associated with aggressive phenotypes of HCC and could be an independent prognostic factor for HCC patients after curative hepatectomy. Meanwhile, we presented the real-time reverse-transcriptase polymerise-chain-reaction (RT-PCR) study in the same cohort of patients on a battery of core genes which play important roles in inflammation (COX2, MMP7, MMP9) [14-16] and angiogenesis (VEGF, PDGFRA) $[17,18]$, as well as MYC which was confirmed as a key hypoxia regulator [19], to find the correlation of HIF$1 \alpha$ with these factors that can also affect and reflect tumor behaviors. These factors were selected for at least two of the three aspects: being crucial in inflammation or angiogenesis; being active in tumor metastasis or invasion; being mechanistically related to hypoxia. At last, using in situ immunostaining of HIF- $1 \alpha$ protein, we got a further confirmation of the clinical significance of this crucial factor.

\section{Methods \\ Patients and Specimens}

Under the following the inclusion and exclusion criteria: (a) distinctive pathologic diagnosis of HCC, (b) without anticancer treatment and distant metastases before surgery, (c) underwent primary and curative resection for HCC between 2002 and 2005, defined as macroscopically complete removal of the tumor, as described previously [20], and (d) with complete clinicopathologic and followup data, about 2000 patients underwent hepatectomy at Zhongshan Hospital, Fudan University between 2002 and 2005 were identified. Following approval by the Institutional Review Board, a total of 110 patients in this time, with available frozen tumor specimens from our prospectively established tissue bank, were chosen randomly to be entered in this retrospective study. The mean age of patients was 52.4 years (range: 28-75) and all the patients were classified with Barcelona Clinic Liver Cancer staging system (BCLC stage) [21]. Informed consent was obtained from all patients.

A diagnosis of recurrence was confirmed by an elevated AFP level and typical imaging appearance in computed tomography and/or magnetic resonance imaging scan [20]. Overall survival (OS) was defined as the interval from surgery and death. Disease-free survival time (DFS) was defined as the interval from surgery to recurrence. The data was censored on last follow-up for living patients or for the patients in whom tumor recurrence was not diagnosed. The median follow-up time was 24.0 months (range: 1.5-68.0 mon; SE: 1.49).

\section{Real-time RT-PCR}

Total RNA was isolated from each specimen with Trizol reagent (Invitrogen, Carlsbad, CA) and then reverse transcribed with the oligo dT primers and SuperScript RT (Invitrogen). The PCR primers used were showed in Table 1. Quantitative real-time RT-PCR was performed by using a 384-well ABI 7900 HT (Applied Biosystems, Foster City, 
Table I: Forward and reverse primers for the genes analyzed

\begin{tabular}{lll}
\hline Gene & Forward primer & Reverse primer \\
\hline HIF-I $\alpha$ & 5'CTGCTGTCTTACTGGTCCTT3' & 5'GTCGCTTCTCCA ATTCTTAC3' \\
COX-2 & 5'CCATTCAGTTCCCACCATCT3' & 5'TCACTGCTGTTGGGTCTCTG3' \\
MMP7 & 5'AGATGTGGAGTGCCAGATGT3' & 5'TAGACTGCTACCATCCGTCC3' \\
MMP9 & 5'GGCGCTCATGTACCCTATGT3' & 5'CCTGTGTACACCCACACCTG3' \\
VEGF & 5'ATGAACTTTCTGCTCTCTGG3' & 5'TCATCTCTCCTATGTGCTGGC3' \\
PDGFRA & 5'GGGGAAACGATTGTGGTCACC3' & 5'CCCGCACCTCTACAACAAAAT3' \\
MYC & 5'AAAGGCCCCCAAGGTAGTTA3' & 5'TTTCCGCAACAAGTCCTCTT3' \\
HPRT & 5'CCTGGCGTCGTGATTAGTG3' & 5'CAGAGGGCTACAATGTGATGG3' \\
\hline TBP & 5'ACCACTCCACTGTATCCCTCC3' & 5'CTGTTCTTCACTCTTGGCTCCT3' \\
\hline
\end{tabular}

CA). In particular, for a single gene, PCR amplifications of all the 110 specimens were simultaneously performed on the same 384-well plate in duplicate to avoid potential variations. Duplicate RT-PCR samples in each assay were collapsed by averaging.

Cycling parameters were as follows: $2 \mathrm{~min}$ at $50^{\circ} \mathrm{C}$ and 10 min at $95^{\circ} \mathrm{C}$ followed by 40 cycles of $30 \mathrm{sec}$ at $95^{\circ} \mathrm{C}$ and $2 \mathrm{~min}$ at $60^{\circ} \mathrm{C}$. The relative changes in gene expression were calculated by the $\Delta \Delta \mathrm{Ct}$ method using the SDS 2.1 software according to the manufacturer's instructions (Applied-Biosystems). The expression of each gene was related to its expression in the reference RNA pool from the 10 normal liver tissues used as a calibrator. To control for variability in cDNA quantity, integrity, and individual primer efficiency, data were normalized against two housekeeping genes (TBP and HPRT) as we previously described [22]. (See Additional file 1: Figure S1 for relative mRNA expression of HIF- $1 \alpha$, COX-2, MMP7, MMP9, VEGF, PDGFRA and MYC with the cut-off value determined by the X-tile software).

\section{Tissue microarray and Immunohistochemistry}

Tissue microarrays (TMA) were constructed as described previously [23]. Triplicates of $1-\mathrm{mm}$-diameter cylinders from representative areas of tumor center, away from necrotic, hemorrhagic and major fibrotic areas, were included in each case, along with different controls (spleen, lymph node, artery and glioma), to ensure reproducibility and homogenous staining of the slides. Serial sections ( $4 \mu \mathrm{m}$ thick) were placed on slides coated with 3aminopropyltriethoxysilane.

Immunohistochemical staining by the streptavidinbiotin-peroxidase complex method was performed as previously described. Rabbit polyclonal antibody to HIF- $1 \alpha$ (ab65979; Abcam, Cambridge, UK) was used at a dilution of 1:50. Briefly, sections were dewaxed, hydrated, and washed. After neutralization of endogenous peroxidase and microwave antigen retrieval, slides were preincubated with blocking serum and then incubated overnight with the primary Ab. Then, the sections were serially rinsed, incubated with second antibodies, and treated with horseradish peroxidase-conjugated streptavidin. Reaction products were visualized with 3, 3'-diaminobenzidine tetrahydrochloride and counterstained with hematoxylin. For the negative control, the primary antibodies were replaced with phosphate buffered saline.

The manual evaluation of HIF- $1 \alpha$ expression involved location and degree of reactivity. Location of expression included not only the cell type but also that of the subcellular localization (i.e., nucleus, cytoplasm). Degree of expression was determined by assessing semiquantitatively percentage of positive nuclear staining cells in random four fields of each core as well as evaluating for cytoplasmic staining intensity in the entire disk. The final result was classified as follows: I, no staining; II, nuclear staining in less than $10 \%$ of cells and/or with weak cytoplasmic staining; III, nuclear staining in 10\%-50\% of cells and/or with moderate cytoplasmic staining; IV, nuclear staining in more than $50 \%$ of cells and/or with strong cytoplasmic staining [24] In statistical analysis, the grades I and II were considered to be low expression of HIF- $1 \alpha$ protein, with III and IV as high expression [25]. (See Additional file 2: Table S1 for degree of HIF-1 $\alpha$ immunohistochemical staining)

Two independent investigators blind to the clinicopathologic data assessed the immunohistochemistry. When independent scoring of a case differed, the case was rechecked, and the final score was determined by recounting HIF- $1 \alpha$ positive nuclear staining cells using a multiheaded microscope with both reviewers simultaneously viewing the slides.

\section{Statistical analysis}

The statistical analysis was done with SPSS 15.0 program. To assess the relationship between experimental results and clinicopathologic characteristics, Fisher's exact test and Spearman's $\rho$ coefficients test were carried out as appropriate. To find out the correlations between HIF-1 $\alpha$ and other evaluated factors, Pearson Correlation test was used. 
Patient survival distribution was calculated using the Kaplan-Meier method and compared with the log-rank test. Cut-point value of experiment results was determined by the X-tile software [26]. Univariate and multivariate analyses were based on the Cox proportional hazards regression model. All variables that were found to be statistical significant in univariate analysis were included in multivariate analysis. $P<0.05$ (two-sided) was judged statistically significant.

\section{Results}

Correlation of HIF-I mRNA to clinicopathologic features

According to the optimal cut-point value of HIF- $1 \alpha$ determined by the X-tile software, the expression of HIF-1 $\alpha$ mRNA was defined as high expression in 42 specimens (38.2\%) and low expression in 68 specimens (61.8\%). The HIF-1 $\alpha$ mRNA expression level has no correlation to gender, tumor size, encapsulation, number, hepatitis history, liver cirrhosis and preoperative AFP level, while older patients seems to have tumor with higher HIF-1 $\alpha$ expression $(P=0.049)$ (Table 2$)$.

The HIF-1 $\alpha$ mRNA expression level showed significantly positive correlation with vascular invasion. In all the 110 patients, 59 cases without tumor vascular invasion have a high expression rate of $28.8 \%$, as compared with the high expression rate of $49.0 \%(P=0.033)$ in cases with vascular invasion. Also, the HIF-1 $\alpha$ mRNA expression level was significantly correlated to BCLC stages. The HIF- $1 \alpha$ mRNA expression in patients at stage A was lower than those at stages $\mathrm{B}$ and $\mathrm{C}(P=0.041)$ (Table 2$)$.

\section{Correlation of HIF-I to COX-2, MMP7, MMP9, VEGF, PDGFRA and MYC}

Significant positive correlations were observed between HIF- $1 \alpha$ mRNA and the putative markers of inflammation, angiogenesis and MYC: COX-2 $(P<0.001, r=0.708)$, MMP7 $(P<0.001, r=0.593)$, MMP9 $(P<0.001, r=$ $0.384)$, PDGFRA $(P<0.001, r=0.493)$ and MYC $(P<$ $0.001, r=0.230)$. However, there were no significant correlation between mRNA expression level of HIF- $1 \alpha$ and VEGF $(P<0.183, r=0.128)$. Of all the six parameters, COX-2, MMP7 and PDGFRA were the top three factors with the largest correlation coefficients to HIF-1 $\alpha$ (Table 3).

\section{Prognosis}

The OS and DFS rates were $80.0 \%$ and $67.6 \%$ at 1 year, and $51.4 \%$ and $43.7 \%$ at 5 years respectively, for the whole study population.

On univariate analysis, sex, hepatitis history, cirrhosis, ALT level showed no prognostic significance for OS and DFS. AFP, $\gamma$-GT, tumor differentiation, size, vascular invasion and encapsulation were found to be significant pre-
Table 2: Correlations of HIF-I $\alpha$ mRNA and protein with clinicopathological characters

\begin{tabular}{|c|c|c|c|c|c|c|}
\hline & \multicolumn{3}{|c|}{ HIF-I $\alpha$ mRNA } & \multicolumn{3}{|c|}{ HIF-I $\alpha$ protein } \\
\hline & low & high & $P$ & low & high & $P$ \\
\hline Patients & 68 & 42 & & 71 & 39 & \\
\hline \multicolumn{7}{|l|}{ Age(years) } \\
\hline$\leq 52$ & 28 & 26 & 0.049 & 32 & 22 & 0.320 \\
\hline$>52$ & 40 & 16 & & 39 & 17 & \\
\hline \multicolumn{7}{|l|}{ Sex } \\
\hline Male & 57 & 38 & 0.40 & 57 & 38 & 0.017 \\
\hline Female & 11 & 4 & & 14 & 1 & \\
\hline \multicolumn{7}{|c|}{ Hepatitis history } \\
\hline Yes & 61 & 39 & 0.739 & 62 & 38 & 0.094 \\
\hline No & 7 & 3 & & 9 & 1 & \\
\hline \multicolumn{7}{|c|}{ Preoperative AFP(ng/ml) } \\
\hline$\leq 20$ & 29 & 16 & 0.693 & 33 & 12 & 0.156 \\
\hline$>20$ & 39 & 26 & & 38 & 27 & \\
\hline \multicolumn{7}{|c|}{ Liver cirrhosis } \\
\hline Yes & 59 & 34 & 0.428 & 56 & 37 & 0.029 \\
\hline No & 9 & 8 & & 15 & 2 & \\
\hline \multicolumn{7}{|l|}{$\operatorname{ALT}(\mathrm{U} / \mathrm{L})$} \\
\hline$\leq 40$ & 36 & 22 & 1.000 & 38 & 20 & 0.844 \\
\hline$>40$ & 32 & 20 & & 33 & 19 & \\
\hline \multicolumn{7}{|l|}{$\Gamma-\mathrm{GT}(\mathrm{U} / \mathrm{L})$} \\
\hline$\leq 54$ & 30 & 14 & 0.318 & 31 & 13 & 0.316 \\
\hline$>54$ & 38 & 28 & & 40 & 26 & \\
\hline \multicolumn{7}{|c|}{ Tumor size $(\mathrm{cm})$} \\
\hline$\leq 5$ & 35 & 21 & 1.000 & 33 & 23 & 0.236 \\
\hline$>5$ & 33 & 21 & & 38 & 16 & \\
\hline \multicolumn{7}{|c|}{ Tumor encapsulation } \\
\hline Yes & 31 & 18 & 0.845 & 32 & 17 & 1.000 \\
\hline No & 37 & 24 & & 39 & 22 & \\
\hline \multicolumn{7}{|c|}{ Tumor number } \\
\hline Single & 53 & 32 & 0.820 & 56 & 29 & 0.638 \\
\hline Multiple & 15 & 10 & & 15 & 10 & \\
\hline \multicolumn{7}{|c|}{ Vascular invasion } \\
\hline Yes & 26 & 25 & 0.033 & 27 & 24 & 0.027 \\
\hline No & 42 & 17 & & 44 & 15 & \\
\hline \multicolumn{7}{|l|}{ BCLC stage } \\
\hline A & 30 & 10 & $0.04 I$ & 31 & 9 & 0.039 \\
\hline$B+C$ & 38 & 32 & & 40 & 30 & \\
\hline \multicolumn{7}{|c|}{ Tumor differentiation } \\
\hline $1+\|$ & 40 & 18 & 0.119 & 36 & 22 & 0.690 \\
\hline III+IV & 28 & 24 & & 35 & 17 & \\
\hline \multicolumn{7}{|c|}{ Prophylactic treatment } \\
\hline Yes & 33 & 22 & 0.845 & 31 & 24 & 0.110 \\
\hline No & 35 & 20 & & 39 & 16 & \\
\hline
\end{tabular}

Detailed legends: Fisher's exact tests were used for all the analysis of correlations.

dictors for OS. Age, AFP, $\gamma$-GT, tumor size, number, vascular invasion and encapsulation were predictors for DFS (Table 4).

Univariate analysis revealed that the HIF- $1 \alpha$ mRNA expression level was associated with both $\mathrm{OS}(\mathrm{P}=0.001)$ and DFS ( $\mathrm{P}=0.001)$ (Table 4; Figure $1 \mathrm{~A}$ and $1 \mathrm{~B})$. The OS rate for patients with high and low expression of HIF-1 $\alpha$ 
Table 3: Correlations between HIF-I $\alpha$ mRNA and other molecular markers as well as prognostic significance.

\begin{tabular}{cccccccc}
\hline & HIF-I $\alpha$ & COX-2 & MMP7 & PDGFRA & MMP9 & MYC & VEGF \\
\hline Correlation $(P)$ & 0.000 & $<0.001$ & $<0.001$ & $<0.001$ & $<0.001$ & 0.016 & 0.183 \\
Coefficient $(r)$ & 1.000 & 0.708 & 0.593 & 0.493 & 0.384 & 0.230 & 0.128 \\
OS $(P)$ & 0.012 & 0.004 & 0.010 & 0.010 & NS & NS & NS \\
DFS $(P)$ & 0.004 & 0.010 & NS & 0.038 & NS & NS & NS \\
\hline
\end{tabular}

Detailed legends: The $P$ values for correlation were determined by spearman's coefficience. The $P$ values for OS and DFS were calculated using multivariate Cox proportional hazards analysis. All factors were presented in different multivariable analysis respectively and variables were adopted for their prognostic significance by univariate analysis. NS means not significant $(P>0.05)$.

mRNA were $63.2 \%$ and $88.9 \%$ at 1 year $(P=0.001)$, $30.4 \%$ and $62.5 \%$ at 5 year $(P=0.001)$ respectively. Similarly, the DFS rate for patients with high and low expression were $53.9 \%$ and $74.3 \%$ at 1 year $(P=0.004), 20.4 \%$ and $54.8 \%$ at 5 year $(P=0.004)$ respectively.

Further, multivariate analysis confirmed that HIF- $1 \alpha$ mRNA expression was independent prognostic factor for OS $(P=0.012$, hazard ratio: $2.167,95 \% \mathrm{CI}: 1.185-3.965)$ and DFS ( $P=0.004$, hazard ratio: $2.359,95 \% \mathrm{CI}: 1.325-$ $4.201)$. In addition, for DFS, the $P$ value was the smallest and the hazard ratio was the largest among these factors (Table 5 and Additional files 3, 4, 5, 6, 7 and 8 ).

Also, as for mRNA expression, COX-2 and PDGFRA, being correlated with HIF-1 $\alpha$ with larger coefficients among the six parameters, showed significance for both OS and DFS on univariate analysis (COX-2: $\mathrm{P}=0.014$ for $\mathrm{OS}, \mathrm{P}=0.027$ for DFS; PDGFRA: $\mathrm{P}=0.044$ for OS, $\mathrm{P}=0.041$ for DFS) and then strengthened on multivariate analysis (COX-2: $\mathrm{P}$ $=0.004$ for OS, $\mathrm{P}=0.010$ for DFS; PDGFRA: $\mathrm{P}=0.010$ for OS, $\mathrm{P}=0.038$ for DFS). MMP7, which also correlated with HIF-1 $\alpha$, showed significance for OS on both uni- and multi-variate analyses, and patients with high MMP7 had a propensity of increased recurrence $(P=0.060)$. However, VEGF was only significant for DFS $(P=0.022)$ but has no influence on OS $(P=0.299)$ in univariate analysis. On multivariate analysis, VEGF was not a significant prognostic factor for recurrence $(\mathrm{P}=0.081)$ any more. Neither MMP9 ( $\mathrm{P}=0.313$ for OS, $\mathrm{P}=0.607$ for DFS) nor MYC ( $\mathrm{P}$ $=0.862$ for OS, $\mathrm{P}=0.361$ for DFS) had any prognostic value for either OS or DFS in HCC. (Tables 4 and 5)

Table 4: Univariate analyses of factors associated with survival and recurrence

\begin{tabular}{|c|c|c|c|c|}
\hline \multirow[t]{2}{*}{ Variables } & \multicolumn{2}{|l|}{ os } & \multicolumn{2}{|c|}{ FS } \\
\hline & Hazard ratio( $95 \% \mathrm{Cl})$ & $P$ & Hazard ratio(95\%Cl) & $\mathbf{P}$ \\
\hline Age (year) & $0.982(0.958-1.006)$ & 0.142 & $0.976(0.953-0.999)$ & 0.043 \\
\hline Sex (female vs. male) & $0.630(0.250-1.588)$ & 0.298 & $0.673(0.288-1.574)$ & 0.361 \\
\hline Hepatitis history (no vs. yes) & $1.384(0.498-3.848)$ & 0.534 & $0.874(0.395-1.935)$ & 0.739 \\
\hline Liver cirrhosis (no vs. yes) & $1.855(0.746-4.657)$ & 0.190 & $0.904(0.455-1.797)$ & 0.773 \\
\hline $\operatorname{AFP}(\mathrm{ng} / \mathrm{ml})(\leq 20$ vs. $>20)$ & $2.183(1.175-4.035)$ & 0.013 & $2.553(\mathrm{I} .40 \mathrm{I}-4.65 \mathrm{I})$ & 0.002 \\
\hline $\operatorname{ALT}(\mathrm{U} / \mathrm{L})(\leq 40$ vs. $>40)$ & $0.877(0.502-1.533)$ & 0.645 & $0.817(0.476-1.401)$ & 0.463 \\
\hline$\gamma$-GT(U/L) $(\leq 54$ vs. >54) & $2.475(1.313-4.664)$ & 0.005 & $1.555(0.888-2.722)$ & 0.123 \\
\hline Tumor differentiation (I+II vs. III+IV) & $1.860(1.062-3.297)$ & 0.030 & $1.180(0.691-2.014)$ & 0.545 \\
\hline Tumor size $(\mathrm{cm})$ & $1.179(1.109-1.253)$ & 0.001 & $1.152(1.083-1.226)$ & 0.001 \\
\hline Tumor number (single vs. multiple) & $1.597(0.860-2.966)$ & 0.138 & $2.85 I(1.611-5.046)$ & 0.001 \\
\hline Vascular invasion (no vs. yes) & $5.706(2.97 \mid-10.960)$ & 0.001 & $4.028(2.288-7.089)$ & 0.001 \\
\hline Encapsulation (complete vs. no) & $2.060(1.135-3.737)$ & 0.017 & $3.273(1.773-6.044)$ & 0.001 \\
\hline$B C L C$ stage $(A$ vs. $B+C)$ & $6.225(2.645-14.647)$ & 0.001 & 2.601 (1.390-4.867) & 0.003 \\
\hline COX-2 mRNA (low vs. high) & $2.042(1.157-3.604)$ & 0.014 & $1.839(1.068-3.167)$ & 0.027 \\
\hline MMP7 mRNA (low vs. high) & $2.278(1.297-4.001)$ & 0.004 & $0.753(0.409-1.384)$ & 0.060 \\
\hline MMP9 mRNA (low vs. high) & $0.740(0.4 \mid 2-1.328)$ & 0.313 & $1.711(0.977-2.995)$ & 0.609 \\
\hline VEGF mRNA (low vs. high) & $1.370(0.756-2.483)$ & 0.299 & $1.906(1.096-3.126)$ & 0.022 \\
\hline PDGFRA mRNA (low vs. high) & $1.801(1.017-3.188)$ & 0.044 & $1.771(1.023-3.066)$ & 0.041 \\
\hline MYC mRNA (low vs. high) & $0.948(0.517-1.735)$ & 0.862 & $0.867(0.501-1.499)$ & 0.361 \\
\hline HIF-I $\alpha$ mRNA (low vs. high) & $2.644(1.524-4.655)$ & 0.001 & $2.514(1.462-4.324)$ & 0.001 \\
\hline HIF-I $\alpha$ protein (low vs. high) & $1.874(1.074-3.270)$ & 0.027 & $2.004(1.167-3.440)$ & 0.012 \\
\hline
\end{tabular}

Detailed legends: The $P$ values were calculated using univariate Cox proportional hazards analysis. Cut-point values of the experiment results were determined by the $\mathrm{X}$-tile software. 

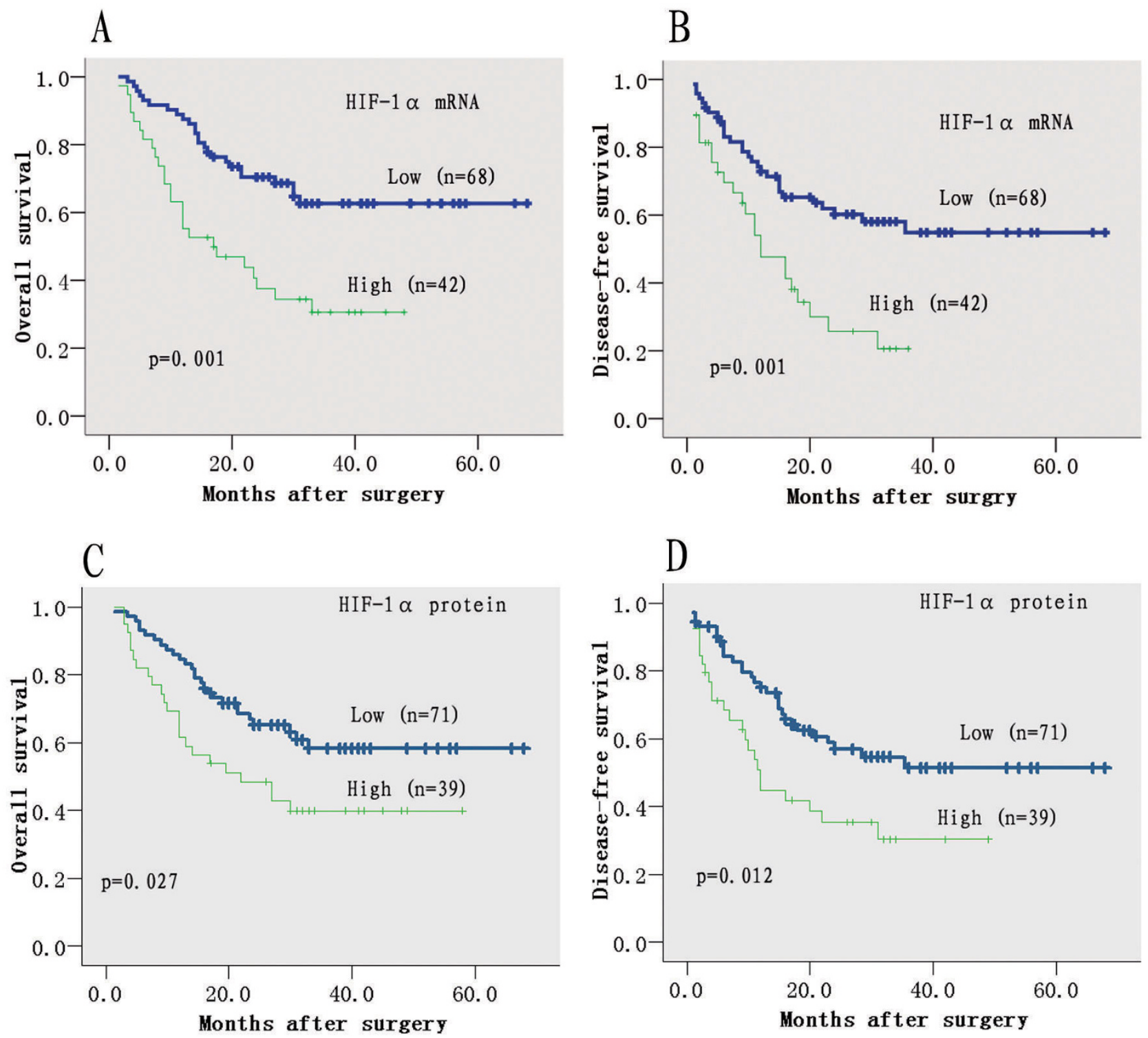

\section{Figure I}

Kaplan-Meier analysis of overall and disease-free survival for HIF-I $\alpha$ mRNA and protein. Low expression of HIF$I \propto$ mRNA $(A, B)$ or protein $(C, D)$ was associated with both prolonged survival and reduced recurrence. The $P$ values were determined by the log-rank test.

\section{Immunohistochemical confirmation}

In HCC, positive staining of HIF- $1 \alpha$ protein was observed mainly in cancer cells, and occasionally in infiltrating lymphocytes as well. In contrast, the fibroblasts and endothelial cells in tumor tissue always showed negative staining. HIF-1 $\alpha$ protein was commonly detected in cytoplasm, whereas in some cases HIF-1 $\alpha$ protein was detected mostly in nucleus. Representative images were showed in Figure 2.
According to the optimal cut-point determined by the $\mathrm{X}$ tile software, there were $71(64.5 \%)$ patients with low expression and 39 (35.5\%) patients with high expression. Although the immunohistochemical results were not totally in parallel with the RT-PCR results, protein expression of HIF-1 $\alpha$ were highly correlated with the mRNA expression $(P=0.001)$. (See Additional file 9: Table S2 for correlations between HIF- $1 \alpha$ mRNA and protein) 
Table 5: Multivariate analyses of factors associated with survival and recurrence

\begin{tabular}{|c|c|c|}
\hline & Hazard ratio $(95 \% \mathrm{Cl})$ & $P$ \\
\hline \multicolumn{3}{|l|}{ OS } \\
\hline $\operatorname{AFP}(\mathrm{ng} / \mathrm{ml})(\leq 20$ vs. $>20)$ & $1.320(0.666-2.615)$ & 0.426 \\
\hline$\gamma-\mathrm{GT}(\mathrm{U} / \mathrm{l})(\leq 54$ vs. $>54)$ & $2.098(1.073-4.103)$ & 0.030 \\
\hline Tumor differentiation (I+II vs. III+IV) & $1.228(0.661-2.279)$ & 0.516 \\
\hline Tumor size $(\mathrm{cm})$ & $1.102(1.016-1.196)$ & 0.020 \\
\hline Vascular invasion (no vs. yes) & 4.351 (1.992-9.500) & 0.001 \\
\hline Capsule (complete vs. no) & $0.676(0.332-1.375)$ & 0.280 \\
\hline HIF-I $\alpha$ mRNA (low vs. high) & $2.167(1.185-3.965)$ & 0.012 \\
\hline COX-2 mRNA (low vs. high) & $2.557(1.355-4.824)$ & 0.004 \\
\hline MMP7 mRNA (low vs. high) & $2.287(1.217-4.301)$ & 0.010 \\
\hline PDGFRA mRNA (low vs. high) & $2.320(1.225-4.394)$ & 0.010 \\
\hline HIF-I $\alpha$ protein (low vs. high) & $2.108(1.120-3.969)$ & 0.021 \\
\hline \multicolumn{3}{|l|}{ DFS } \\
\hline Age (year) & $0.990(0.963-1.018)$ & 0.475 \\
\hline $\operatorname{AFP}(\mathrm{ng} / \mathrm{ml})(\leq 20$ vs. $>20)$ & $1.707(0.903-3.227)$ & 0.100 \\
\hline Tumor size $(\mathrm{cm})$ & $1.090(0.997-1.191)$ & 0.060 \\
\hline Tumor number (single vs. multiple) & $3.324(1.818-6.079)$ & 0.001 \\
\hline Vascular invasion (no vs. yes) & $2.453(1.192-5.047)$ & 0.015 \\
\hline Encapsulation (complete vs. no) & $1.573(0.78 \mathrm{I}-3.168)$ & 0.204 \\
\hline HIF-I $\alpha$ mRNA (low vs. high) & $2.359(1.325-4.20 I)$ & 0.004 \\
\hline COX-2 mRNA (low vs. high) & $2.170(1.201-3.921)$ & 0.010 \\
\hline MMP7 mRNA (low vs. high) & $1.499(0.830-2.707)$ & 0.179 \\
\hline VEGF mRNA (low vs. high) & $1.702(0.936-3.094)$ & 0.081 \\
\hline PDGFRA mRNA (low vs. high) & $1.910(1.038-3.514)$ & 0.038 \\
\hline HIF-I $\alpha$ protein (low vs. high) & $2.265(1.251-4.009)$ & 0.007 \\
\hline
\end{tabular}

Detailed legends: The $P$ values were calculated using multivariate Cox proportional hazards analysis. Variables were adopted for their prognostic significance by univariate analysis and no significant correlation between each other. COX-2 mRNA, PDGFRA mRNA, MMP7 mRNA, VEGF mRNA and HIF-I $\alpha$ protein were presented in different multivariable analysis respectively. (For details see Additional files 3, 4, 5, 6, 7 and 8)

The tumor HIF-1 $\alpha$ protein expression level has no association with patient age, tumor size, number, encapsulation, hepatitis history and preoperative AFP. Similar to HIF- $1 \alpha$ mRNA, the tumor HIF-1 $\alpha$ protein expression level was significantly associated with tumor vascular invasion $(P=0.027)$ and BCLC stages $(P=0.039)$. (Table 2$)$

High expression of protein also means the poor outcome. Both OS and DFS were better in low expression group than that of high expression group. The OS rates for patient with high and low expression of HIF-1 $\alpha$ protein were $69.2 \%$ and $85.9 \%$ at 1 year $(P=0.015), 39.8 \%$ and $58.0 \%$ at 5 years $(P=0.015)$ respectively. Also, the DFS rates for high and low expression were $50.8 \%$ and $76.5 \%$ at 1 year $(P=0.009), 30.3 \%$ and $51.2 \%$ at 5 year $(P=$ $0.009)$ respectively.

On univariate analysis, tumor HIF-1 $\alpha$ protein expression level was significant for both OS $(P=0.027)$ and DFS $(P$ $=0.012$ ) (Table 4; Figure $1 \mathrm{C}$ and $1 \mathrm{D})$, which were further authenticated on multivariate analysis $(P=0.021$ for OS; $P=0.007$ for DFS) (Table 5). These may indicate that the prognostic value of HIF- $1 \alpha$ was further validated on protein level.

\section{Discussion}

It has been established that human solid tumors develop a pathophysiologic microenvironment during growth, characterized by an irregular microvascular network and regions of hypoxia [7]. Of clinical importance, hypoxiarelated genes and proteins are potentially alternative endogenous markers, as compared with the inability and the cost of exogenous hypoxia markers [2]. In this study, we demonstrated for the first time that HIF-1 $\alpha$, at both mRNA and protein levels, is an independent prognostic factor for both survival and recurrence in HCC with the smallest $P$ value as well as the largest hazard ratio for recurrence. In addition, we found that high expression of HIF-1 $\alpha$ was significantly associated with an advanced stage and aggressive phenotypes. Several in vitro experimental studies sustained our results. In rat HCC models, tumor progression after hypoxia and chemotherapy was related to up-regulation of HIF- $1 \alpha$ and subsequent VEGF production, and transcriptional blockade of HIF- $1 \alpha$ could enhance their therapeutic efficacy [27]. In cell lines, HCC cell proliferation was inhibited by HIF- $1 \alpha$ antisense oligonuclecotide [28]. As a key player in tumor progression, HIF- $1 \alpha$ overexpression is associated with an increased mortality and treatment failure in various cancers 
A

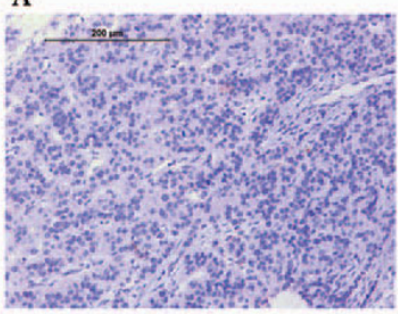

C

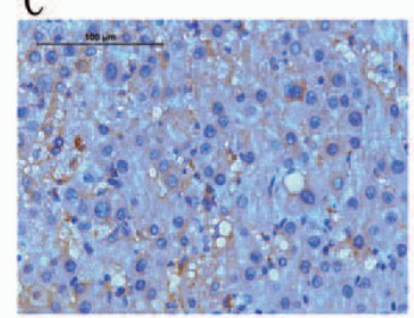

E

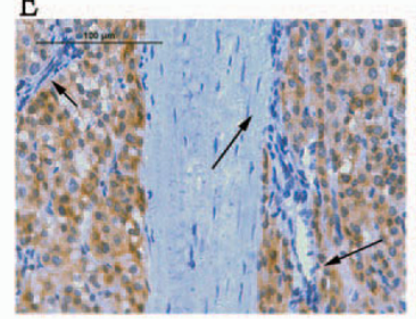

B

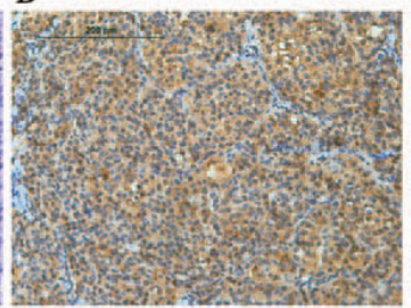

D

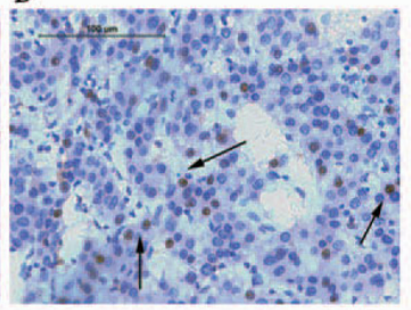

$\mathrm{F}$

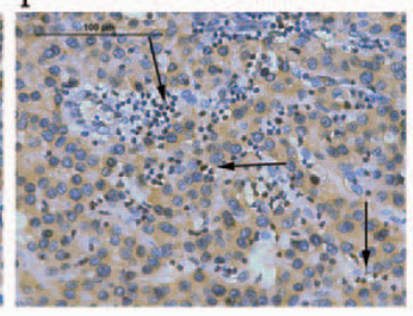

Figure 2

Representative images of immunohistochemical staining. A: Negative expression of HIF-I $\alpha$ protein $(\times 200)$. B: Positive expression of HIF-I $\alpha$ protein $(\times 200)$. C: HIF-I $\alpha$ protein localized in the cytoplasm $(\times 400)$. D: HIF-I $\alpha$ protein localized in the nucleus (arrows) $(\times 400)$. E: Negative staining in fibroblasts and endothelial cells (arrows) $(\times 400)$. F: Positive staining in lymphocytes (arrows) $(\times 400)$.

although conflicting data exist [7]. The current study emphasizes the clinical significance of HIF- $1 \alpha$, suggesting that related therapy in the future is promising in reducing recurrence and prolonging survival [29].

The underlying mechanisms that HIF- $1 \alpha$ affects metastatic spread and selecting cells with more aggressive phenotypes have not been fully defined, but recent studies have shown a role for increased invasive capacity and inflammation [11]. Consistently, we found the importance of HIF- $1 \alpha$ in HCC is associated with or may contribute to other markers related to inflammation, angiogenesis and invasion. COX-2, MMP7 and MMP9 were well-recognized factors in inflammation conditions [14-16]. Among these molecules, COX-2, being involved in the chronic inflammation-related development of HCC, correlated with HIF- $1 \alpha$ with the largest correlation coefficient $(r=0.708)$. Mechanistically, hypoxia potently triggers COX-2 transcription in many kinds of cells in pri-

mary culture [30,31]. Also, hypoxia influences the expression of MMPs although the mechanisms are controversial [5,32]. The mRNA expression of MMP7, which can degrade various ECM proteins and support the role in tumor invasion and spread in HCC, has significant correlation to HIF-1 $\alpha$ mRNA expression in our study $(r=$ $0.593)$. However, MMP9, without any prognostic signifcance, seems to have less significant correlation to HIF- $1 \alpha$ mRNA than MMP7 in HCC $(r=0.383)$. VEGF and PDGFRA promote the tumor angiogenesis in inflammation and hypoxia conditions $[18,33]$. HIF- $1 \alpha$ was often considered a master regulator of VEGF expression and angiogenesis in hypoxia. However, in our study, VEGF has no significant correlations with HIF- $1 \alpha$. As suggested, the regulation of VEGF expression may be come true by HIF-1 $\alpha$ independent pathways in hypoxia [34]. Otherwise, studies have revealed hypoxia can upregulate the expression of PDGFA [10], PDGFB [35] and PDGFRB [36], with little information on the correlation between HIF- $1 \alpha$ and PDGFRA. Our study provide the preliminary data that HIF- $1 \alpha$ positively correlated with and thus may upregulate PDGFRA, also a crucial angiogenic factor, in HCC $(P<0.001, r$ $=0.493)$.

All of these factors were conceived to promote tumor progression. Some of these molecules, such as COX-2, PDGFRA and MMP7, were believed to be prognostic factors in HCC according to our research. COX-2 may regulate HCC growth by COX-2-derived PG signaling pathway [37]. PDGFRA may regulate tumor angiogenesis by PDGFRAp70S6K pathway which is related to the function of fibroblast growth factor (FGF) and expression of VEGF and hepatocytes growth factor (HGF) [18]. MMPs increase HCC invasion and growth through the degradation of extracellar matrix [38].

However, we propose that HIF- $1 \alpha$, with the smallest $P$ value as well as the largest hazard ratio for DFS among these factors, may be the central factor to affect HCC outcome. Extensive researches have confirmed that HIF- $1 \alpha$ controls many hundreds of target genes which play important roles in the cellular adaptation to hypoxia, and the proteins of these genes are involved in processes which can make cancer cells much more aggressive, such as angiogenesis, proliferation, apoptosis, energy metabolism and glucose transportation [29].

In addition, the oncogene MYC also plays a crucial role in hypoxic response, and cooperates with HIF- $1 \alpha$ to alter cellular metabolism and promote cancer progression [19]. In our study, MYC was positive correlated with HIF-1 $\alpha(P=$ $0.016)$. However, the correlation coefficient was small $(r$ $=0.230$ ), and MYC has no prognostic value in HCC. The findings that MYC expression was repressed in the human hepatoma cell lines under extremely low oxygen concen- 
trations may partly responsible for this non-significance [39].

In summary, HIF-1 $\alpha$ was an independent prognosticator for both survival and recurrence in HCC. Although the correlations between HIF- $1 \alpha$ and markers of inflammation, angiogenesis and the cooperative MYC oncogene are not very clear, we can hypothesize that HIF- $1 \alpha$ was the crucial factor in HCC progression on the basis of our findings. The therapy targeting HIF- $1 \alpha$ and associated molecules may profoundly reduce recurrence and prolong survival.

\section{Conclusion}

HIF-1 $\alpha$ was an independent prognosticator for both survival and recurrence in HCC. Markers of inflammation, angiogenesis and the cooperative MYC oncogene, who have closer correlation with HIF- $1 \alpha$, seem to be better for prognostic stratification, suggesting that HIF- $1 \alpha$ was one of the most crucial factors in HCC progression. Attaching importance to HIF-1 $\alpha$ and related molecules may improve the prognostic stratification and therapeutic technique.

\section{Abbreviations}

AFP: alpha-fetoprotein; BCLC stage: Barcelona Clinic Liver Cancer stage; CI: confidence interval; COX-2: cyclooxygenase-2; DFS: disease-free survival; HBV: hepatitis B virus; HCC: hepatocellular carcinoma; HIF-1 $\alpha$ : hypoxia-inducible factor 1, alpha subunit; HPRT: hypoxanthine-guanine phosphoribosyltransferase; MMP: matrix metalloproteinase; OS: overall survival; PDGFRA: platelet-derived growth factor receptor, alpha polypeptide; RT-PCR: polymerase chain reaction; TBP: TATA binding protein; VEGF: vascular endothelial growth factor.

\section{Competing interests}

The authors declare that they have no competing interests.

\section{Authors' contributions}

JF developed the study concept, aims and initiated the project. QG and CXD performed the experimental work described in the study and were both responsible for the drafting of the manuscript. SJQ supervised the process of the whole research. JZ and BHZ provided valuable scientific suggestions. MJJ, MYC and YFX have participated in its design and coordination. All authors have read and approved the final manuscript.

\section{Additional material}

\author{
Additional file 1 \\ Figure S1: Relative expression of HIF-1, COX-2, MMP7, MMP9, \\ VEGF, PDGFRA and MYC with the cut-off value determined by the \\ $X$-tile software. The blue dots show the relative value of mRNA expres- \\ sion. The red lines show the cut-off value. \\ Click here for file \\ [http://www.biomedcentral.com/content/supplementary/1471- \\ 2407-9-418-S1.DOC]
}

\section{Additional file 2}

Table S1: Degree of HIF-1 immunohistochemistry in tissue array of HCC. I, no staining; II, nuclear staining in less than $10 \%$ of cells and/or with weak cytoplasmic staining; III, nuclear staining in 10\%-50\% of cells and/or with moderate cytoplasmic staining; $I V$, nuclear staining in more than $50 \%$ of cells and/or with strong cytoplasmic staining.

Click here for file

[http://www.biomedcentral.com/content/supplementary/14712407-9-418-S2.DOC]

\section{Additional file 3}

Figure S2: Kaplan-Meier analysis of OS and DFS for COX-2, MMP7, MMP9, VEGF, PDGFRA and MYC mRNA

Click here for file

[http://www.biomedcentral.com/content/supplementary/14712407-9-418-S3.DOC]

\section{Additional file 4}

Table S3: Multivariate analyses of variables associated with survival and recurrence including mRNA expression of COX-2 as co-variable Click here for file

[http://www.biomedcentral.com/content/supplementary/14712407-9-418-S4.DOC]

\section{Additional file 5}

Table S4: Multivariate analyses of variables associated with survival and recurrence including $m R N A$ expression of PDGFRA as co-variable Click here for file

[http://www.biomedcentral.com/content/supplementary/14712407-9-418-S5.DOC]

\section{Additional file 6}

Table S5: Multivariate analyses of variables associated with survival and recurrence including $m R N A$ expression of MMP7 as co-variable Click here for file

[http://www.biomedcentral.com/content/supplementary/14712407-9-418-S6.DOC]

\section{Additional file 7}

Table S6: Multivariate analyses of variables associated with survival and recurrence including protein expression of HIF-1 as co-variable. $(P=0.021$ for $O S, P=0.007$ for $D F S)$.

Click here for file

[http://www.biomedcentral.com/content/supplementary/14712407-9-418-S7.DOC] 


\section{Additional file 8}

Table S7: Multivariate analyses of variables associated with survival and recurrence including $m R N A$ expression of VEGF as co-variable. $(P=0.081$ for $D F S)$.

Click here for file

[http://www.biomedcentral.com/content/supplementary/14712407-9-418-S8.DOC]

\section{Additional file 9}

Table S2: Correlations between HIF-1 mRNA and protein expression. Click here for file

[http://www.biomedcentral.com/content/supplementary/14712407-9-418-S9.DOC]

\section{Acknowledgements}

This study was funded by Key Project of the Chinese Ministry of Education (no. 107039), National Key Sci-Tech Special Project of China (no. 2008ZX10002-018, 2008ZX10002-019), National Natural Science Foundation of China (no. 30700794) and the Doctoral Fund of Ministry of Education of China (no. 20060246075).

\section{References}

I. Greten TF, Manns MP, Korangy F: Immunotherapy of HCC. Rev Recent Clin Trials 2008, 3(I):31-39.

2. Vengellur A, Phillips JM, Hogenesch JB, LaPres JJ: Gene expression profiling of hypoxia signaling in human hepatocellular carcinoma cells. Physiol Genomics 2005, 22(3):308-3I8.

3. Gwak GY, Yoon JH, Kim KM, Lee HS, Chung JW, Gores GJ: Hypoxia stimulates proliferation of human hepatoma cells through the induction of hexokinase II expression. J Hepatol 2005, 42(3):358-364.

4. Kim KR, Moon HE, Kim KW: Hypoxia-induced angiogenesis in human hepatocellular carcinoma. J Mol Med 2002, 80(II):703-7I4.

5. Miyoshi A, Kitajima Y, Ide T, Ohtaka K, Nagasawa H, Uto Y, Hori H, Miyazaki K: Hypoxia accelerates cancer invasion of hepatoma cells by upregulating MMP expression in an HIF-Ialpha-independent manner. Int J Oncol 2006, 29(6): 1533-1539.

6. Wu XZ, Xie GR, Chen D: Hypoxia and hepatocellular carcinoma: The therapeutic target for hepatocellular carcinoma. J Gastroenterol Hepatol 2007, 22(8): I I 78- I I 82.

7. Bertout JA, Patel SA, Simon MC: The impact of $\mathrm{O} 2$ availability on human cancer. Nat Rev Cancer 2008, 8(I 2):967-975.

8. Hirota K: Hypoxia-inducible factor I, a master transcription factor of cellular hypoxic gene expression. J Anesth 2002, 16(2):150-159.

9. Klatte $T$, Seligson DB, Riggs SB, Leppert JT, Berkman MK, Kleid MD, Yu H, Kabbinavar FF, Pantuck AJ, Belldegrun AS: Hypoxia-inducible factor I alpha in clear cell renal cell carcinoma. Clin Cancer Res 2007, I 3(24):7388-7393.

10. Hoffmann AC, Mori R, Vallbohmer D, Brabender J, Klein E, Drebber $U$, Baldus SE, Cooc J, Azuma M, Metzger R, et al.: High expression of HIF Ia is a predictor of clinical outcome in patients with pancreatic ductal adenocarcinomas and correlated to PDGFA, VEGF, and bFGF. Neoplasia 2008, 10(7):674-679.

II. Taylor CT: Interdependent roles for hypoxia inducible factor and nuclear factor-kappaB in hypoxic inflammation. J Physiol 2008, 586(Pt I7):4055-4059.

12. Simon JM: Hypoxia and angiogenesis. Bull Cancer 2007, 94(Spec No):S160-165.

13. Gordan JD, Thompson CB, Simon MC: HIF and c-Myc: sibling rivals for control of cancer cell metabolism and proliferation. Cancer Cell 2007, I2(2): 108-II3.

14. Rajakariar R, Yaqoob MM, Gilroy DW: COX-2 in inflammation and resolution. Mol Interv 2006, 6(4): 199-207.

15. Lichtinghagen R, Michels D, Haberkorn Cl, Arndt B, Bahr M, Flemming $\mathrm{P}$, Manns MP, Boeker $\mathrm{KH}$ : Matrix metalloproteinase
(MMP)-2, MMP-7, and tissue inhibitor of metalloproteinase$I$ are closely related to the fibroproliferative process in the liver during chronic hepatitis C. J Hepatol 200I, 34(2):239-247.

16. Reif S, Somech R, Brazovski E, Reich R, Belson A, Konikoff FM, Kessler A: Matrix metalloproteinases 2 and 9 are markers of inflammation but not of the degree of fibrosis in chronic hepatitis C. Digestion 2005, 7 I(2): I24-I30.

17. Li JL, Harris AL: Crosstalk of VEGF and Notch pathways in tumour angiogenesis: therapeutic implications. Front Biosci 2009, |4:3094-3।I0.

18. Tsutsumi N, Yonemitsu Y, Shikada Y, Onimaru M, Tanii M, Okano S, Kaneko K, Hasegawa M, Hashizume M, Maehara Y, et al.: Essential role of PDGFRalpha-p70S6K signaling in mesenchymal cells during therapeutic and tumor angiogenesis in vivo: role of PDGFRalpha during angiogenesis. Circ Res 2004, 94(9): I I86-II 194.

19. Dang CV, Kim JW, Gao P, Yustein J: The interplay between MYC and HIF in cancer. Nat Rev Cancer 2008, 8(I):5I-56.

20. Gao Q, Qiu SJ, Fan J, Zhou J, Wang XY, Xiao YS, Xu Y, Li YW, Tang $Z Y$ : Intratumoral balance of regulatory and cytotoxic $T$ cells is associated with prognosis of hepatocellular carcinoma after resection. J Clin Oncol 2007, 25( I 8):2586-2593.

21. Llovet JM, Bru C, Bruix J: Prognosis of hepatocellular carcinoma: the BCLC staging classification. Semin Liver Dis 1999, 19(3):329-338.

22. Gao Q, Wang XY, Fan J, Qiu SJ, Zhou J, Shi YH, Xiao YS, Xu Y, Huang $X W$, Sun J: Selection of reference genes for real-time PCR in human hepatocellular carcinoma tissues. J Cancer Res Clin Oncol 2008, 134(9):979-986.

23. Gao Q, Wang XY, Qiu SJ, Yamato I, Sho M, Nakajima Y, Zhou J, Li BZ, Shi YH, Xiao YS, et al:: Overexpression of PD-LI significantly associates with tumor aggressiveness and postoperative recurrence in human hepatocellular carcinoma. Clin Cancer Res 2009, I 5(3):97।-979.

24. Zhong H, De Marzo AM, Laughner E, Lim M, Hilton DA, Zagzag D, Buechler $P$, Isaacs WB, Semenza GL, Simons JW: Overexpression of hypoxia-inducible factor I alpha in common human cancers and their metastases. Cancer Res 1999, 59(22):5830-5835.

25. Xie H, Song J, Liu K, Ji H, Shen H, Hu S, Yang G, Du Y, Zou X, Jin H, et al:: The expression of hypoxia-inducible factor-lalpha in hepatitis B virus-related hepatocellular carcinoma: correlation with patients' prognosis and hepatitis $B$ virus $X$ protein. Dig Dis Sci 2008, 53(12):3225-3233.

26. Camp RL, Dolled-Filhart M, Rimm DL: X-tile: a new bio-informatics tool for biomarker assessment and outcome-based cutpoint optimization. Clin Cancer Res 2004, 10(21):7252-7259.

27. Yang ZF, Poon RT, To J, Ho DW, Fan ST: The potential role of hypoxia inducible factor Ialpha in tumor progression after hypoxia and chemotherapy in hepatocellular carcinoma. Cancer Res 2004, 64( I 5):5496-5503.

28. Liu F, Wang P, Jiang X, Tan G, Qiao H, Jiang H, Krissansen GW, Sun $X$ : Antisense hypoxia-inducible factor Ialpha gene therapy enhances the therapeutic efficacy of doxorubicin to combat hepatocellular carcinoma. Cancer Sci 2008, 99(10):2055-206I.

29. Acker T, Plate KH: Hypoxia and hypoxia inducible factors (HIF) as important regulators of tumor physiology. Cancer Treat Res 2004, II 7:219-248.

30. Schmedtje JF Jr, Ji YS, Liu WL, DuBois RN, Runge MS: Hypoxia induces cyclooxygenase-2 via the NF-kappaB p65 transcription factor in human vascular endothelial cells. J Biol Chem 1997, 272(I):601-608.

31. Hierholzer C, Harbrecht BG, Billiar TR, Tweardy DJ: Hypoxiainducible factor- $I$ activation and cyclo-oxygenase-2 induction are early reperfusion-independent inflammatory events in hemorrhagic shock. Arch Orthop Trauma Surg 200I, I 2 I(4):219-222.

32. Osinsky SP, Ganusevich II, Bubnovskaya LN, Valkovskaya NV, Kovelskaya AV, Sergienko TK, Zimina SV: Hypoxia level and matrix metalloproteinases-2 and -9 activity in Lewis lung carcinoma: correlation with metastasis. Exp Oncol 2005, 27(3):202-205.

33. Scaldaferri $F$, Vetrano $S$, Sans $M$, Arena $V$, Straface $G$, Stigliano $E$, Repici A, Sturm A, Malesci A, Panes J, et al.: VEGF-A links angiogenesis and inflammation in inflammatory bowel disease pathogenesis. Gastroenterology 2009, 136(2):585-595. 
34. Arany Z, Foo SY, Ma Y, Ruas JL, Bommi-Reddy A, Girnun G, Cooper M, Laznik D, Chinsomboon J, Rangwala SM, et al.: HIF-independent regulation of VEGF and angiogenesis by the transcriptional coactivator PGC-I alpha. Nature 2008, 45 I (7 I I I): I008-10I2.

35. Eng E, Holgren C, Hubchak S, Naaz P, Schnaper HW: Hypoxia regulates PDGF-B interactions between glomerular capillary endothelial and mesangial cells. Kidney Int 2005, 68(2):695-703.

36. Zhang SX, Gozal D, Sachleben LR Jr, Rane M, Klein JB, Gozal E: Hypoxia induces an autocrine-paracrine survival pathway via platelet-derived growth factor (PDGF)-B/PDGF-beta receptor/phosphatidylinositol 3-kinase/Akt signaling in RN46A neuronal cells. FASEB J 2003, I7( I 2): |709-I7|I.

37. Wu T: Cyclooxygenase-2 in hepatocellular carcinoma. Cancer Treat Rev 2006, 32(I):28-44.

38. Matsunaga $Y$, Koda M, Murawaki $Y$ : Expression of matrix metalloproiteinases (MMPs) and tissue inhibitors of metalloproteinases (TIMPs) in hepatocellular carcinoma tissue, compared with the surrounding non-tumor tissue. Res Commun Mol Pathol Pharmacol 2004, I I5-I 16:143-150.

39. Mazure NM, Chauvet C, Bois-Joyeux B, Bernard MA, Nacer-Cherif $\mathrm{H}$, Danan JL: Repression of alpha-fetoprotein gene expression under hypoxic conditions in human hepatoma cells: characterization of a negative hypoxia response element that mediates opposite effects of hypoxia inducible factor-I and c-Myc. Cancer Res 2002, 62(4): I I58-1 I 65.

\section{Pre-publication history}

The pre-publication history for this paper can be accessed here:

http://www.biomedcentral.com/1471-2407/9/418/pre pub

Publish with Bio Med Central and every scientist can read your work free of charge

"BioMed Central will be the most significant development for disseminating the results of biomedical research in our lifetime. "

Sir Paul Nurse, Cancer Research UK

Your research papers will be:

- available free of charge to the entire biomedical community

- peer reviewed and published immediately upon acceptance

- cited in PubMed and archived on PubMed Central

- yours - you keep the copyright 